\title{
Epidemiology and contact tracing assessment of COVID-19 and potential risk of transmission at different exposure settings: A prospective cohort study
}

Abu Shadat M Noman

Bangamata National Cellular and Molecular Research Centre

Mohammed Rezaul Karim

Parkview Hospital

ASM Zahed

Parkview Hospital

ATM Rezaul Karim

Parkview Hospital

Syed S Islam ( $\sim$ sislam83@kfshrc.edu.sa )

King Faisal Specialist Hospital and Research Centre Riyadh

\section{Research Article}

Keywords: COVID-19, transmission risk, exposure risk, contact tracing

Posted Date: April 22nd, 2021

DOI: https://doi.org/10.21203/rs.3.rs-442709/v1

License: (c) (1) This work is licensed under a Creative Commons Attribution 4.0 International License.

Read Full License 


\section{Abstract}

Background: Transmission risk of coronavirus disease 2019 (COVID-19) to close contacts and at different exposure settings are yet to be fully understood for the evaluation of effective control measures.

Methods: We traced 1171 close contact cases who were linked to 291 index cases between July 3, 2020 and September 3, 2020. Clinical and epidemiological characteristics of all index cases, close contacts, and secondary contact cases were collected and analyzed the secondary attack rate and risk of transmission at different exposure settings.

Results: Median age of 291 index cases were 43.0 years (range 18.5-82.3) including 213 male and 78 females. Among all 1171 close contact cases, 39(3.3\%) cases were identified as secondary infected cases. Among 39 secondary cases, 33(84.62\%) cases were symptomatic and 3 (7.69\%) cases were asymptomatic. Of the 33 symptomatic cases, $31(86.1 \%)$ male and 5(13.9\%) female. Of these 36 symptomatic cases, 24(66.7\%) cases between age 20-59 and remaining 12(33.3\%) cases were age 60 and over. Of the 36 symptomatic cases, $11(30.6 \%)$ cases were identified as severe, 19(52.8\%) as moderate and $6(16.7 \%)$ as mild. The overall secondary clinical attack rate was $3.07 \%(95 \% \mathrm{Cl} 2.49-3.64)$. The attack rate was higher among those aged between 50 to 69 years and shows higher risk of transmission than age below 50 years. The attack rate was higher among household contact $(6.17 \%$ (95\% Cl 4.7-7.6; risk ratio $2.44[95 \% \mathrm{Cl} 1.5-3.4])$, and lower in hospital facility $(2.29 \%, 95 \% \mathrm{Cl} 0.58-3.40$; [risk ratio $0.91,95 \% \mathrm{Cl} 0.17-1.9])$, funeral ceremony $(2.53 \%, 95 \% \mathrm{Cl} 0.32-4.73)$, work places $(3.95 \%, 95 \% \mathrm{Cl} 2.5-5.42$ [risk ratio $1.56,95 \% \mathrm{Cl} 0.63-2.5])$, family contacts $(3.87 \%, 95 \% \mathrm{Cl} 2.4-5.3$; risk ratio $1.53,95 \% \mathrm{Cl} 0.61-2.45]$ ]).

Conclusions: Among all exposure settings analyzed, household contact exposure setting remained the highest transmission probability and risk of transmission of COVID-19 with the increase of age and disease severity.

\section{Background}

As of April 14, 2021, there have been 137 millions confirmed cases and at least 1.96 millions confirmed deaths reported worldwide due to the severe acute respiratory syndrome coronavirus 2 (SARS-CoV-2; COVID-19) in two hundred and fifteen countries ${ }^{1}$. COVID-19 is characterized by several common clinical features, such as fever, pneumonia, shortness of breath, fatigue and in the most severe cases respiratory tract symptoms ${ }^{2,3}$.

Contact tracing is a useful and cost-effective tool for assessing and controlling the transmission of many infectious diseases such as Ebola, SARS, MERS and tuberculosis. If the pre-symptomatic cases from a community are well traced and monitored it becomes easier to manage the transmission as opposed to costly entire lockdowns. Therefore, a well-established tracing and monitoring program increases the probability of rapid identification and isolation of cases and quarantine to restrict further secondary transmission of the virus. Secondary transmission through social interaction and other type of close contacts may change the overall transmission dynamics. Several recent literature highlighted that many 
secondary cases through different exposure settings play a significant role in the outbreak of COVID-19 4-6. The reports on epidemiological characteristics, transmission dynamics and the risk factors of COVID19 in various exposure settings is rapidly growing. Tracing and identifying the close contacts, analyzing secondary transmission and potential risk of transmission in different exposure settings is essential to control transmission of the virus and to develop targeted control and prevention.

On March 8, 2020, three COVID-19 cases were confirmed in Bangladesh, where two individuals were repatriated from Italy, and a third individual was a female relative of one of the two aged between 20 and 35 [IEDCR, 2020]. These individuals had no visible significant signs of illness and passed the airport surveillance. During this same time period, other returnees arrived from the USA, several middle east countries and India in March 2020. As of April 13, 2021 (at the time of the manuscript submission), there were 698,000 laboratory confirmed COVID-19 cases and 9,891 deaths were recorded [IEDCR, 2021]. Using contact tracing data, we examined the epidemiological characteristics and secondary attack rate and risk factors at different exposure settings in a cohort study of 1171 close contacts of 291 index cases of COVID-19 from Bangladesh.

\section{Results}

\section{Characteristics of index cases}

Between July 3, 2020 and September 3, 2020, 291 laboratory-confirmed SARS-CoV-2 infected cases were identified in a densely populated district Chattogram, Bangladesh. Table 1 shows the demographic characteristics of all index cases. Among all cases, 103 (35.4\%) were detected through contact-based surveillance while remaining 188 (64.6\%) were found after symptom-based surveillance (Table 1). Among all reported cases, $213(73.2 \%)$ were male and $78(26.8 \%)$ were female. The mean age of all cases was 43.0 years (ranges from 19 to 83), and 29 (9.97\%) cases were in the age group between 0-29, 224 (76.98\%) cases were in the age group between 30-69 and remaining $38(13.06 \%)$ cases were in the age group 70 and above. When patients were classified based on the disease severity, 145 (49.83\%) cases were mild, 87 (29.9\%) cases were moderate and 59 (20.3\%) cases were severe/critical in nature. Of 291 cases, 258 (88.7\%) were symptomatic, while 33 (11.34\%) did not show any symptom (Table 1$)$. 
Table 1

Demographic and clinical characteristics of 291 Covid-19 index cases identified by contact based $(n=$ 103) and symptom based $(n=188)$ surveillance.

\begin{tabular}{|c|c|c|c|c|}
\hline $\begin{array}{l}\text { All Index cases } \\
n=291\end{array}$ & & $\begin{array}{l}\begin{array}{l}\text { Contact } \\
\text { based }\end{array} \\
\text { surveillance } \\
n=103(\%)\end{array}$ & $\begin{array}{l}\text { Symptom based } \\
\text { surveillance } \\
n=188(\%)\end{array}$ & $\begin{array}{l}\text { p-value } \\
\text { (Fisher } \\
\text { Exact -test) }\end{array}$ \\
\hline \multicolumn{5}{|l|}{ Sex } \\
\hline Male & $\begin{array}{l}213 \\
(73.20)\end{array}$ & 79 (76.70) & $134(71.28)$ & \multirow[t]{2}{*}{$<0.0001$} \\
\hline Female & $78(26.80)$ & $24(23.30)$ & $54(28.72)$ & \\
\hline \multicolumn{5}{|c|}{ Age group (Years) } \\
\hline $0-9$ & 0 & 0 & 0 & \multirow[t]{9}{*}{0.050} \\
\hline $10-19$ & $5(1.72)$ & $1(0.97)$ & $4(4.13)$ & \\
\hline $20-29$ & $24(8.25)$ & $2(1.94)$ & $21(11.17)$ & \\
\hline $30-39$ & $59(20.27)$ & $25(24.27)$ & 35 (18.62) & \\
\hline $40-49$ & $67(23.02)$ & $28(27.18)$ & $47(25.0)$ & \\
\hline $50-59$ & $71(24.40)$ & $21(20.39)$ & $32(17.02)$ & \\
\hline $60-69$ & $27(9.28)$ & $15(14.56)$ & $17(9.04)$ & \\
\hline $70-79$ & $20(6.87)$ & $5(4.85)$ & $13(6.91)$ & \\
\hline $80+$ & $18(6.19)$ & $6(5.83)$ & $19(10.11)$ & \\
\hline \multicolumn{5}{|l|}{ Disease Severity } \\
\hline Mild & $\begin{array}{l}145 \\
(49.83)\end{array}$ & $51(49.51)$ & $94(14.89)$ & \multirow[t]{3}{*}{0.77} \\
\hline Moderate & $87(29.90)$ & $29(28.16)$ & $58(30.85)$ & \\
\hline Severe & $59(20.27)$ & $23(22.33)$ & $36(19.15)$ & \\
\hline \multicolumn{5}{|c|}{ Symptomatic cases } \\
\hline Yes & $\begin{array}{l}258 \\
(88.66)\end{array}$ & $93(90.29)$ & 165 (87.77) & \multirow[t]{2}{*}{0.56} \\
\hline No & $33(11.34)$ & $10(9.71)$ & $23(12.23)$ & \\
\hline \multicolumn{5}{|l|}{ Symptoms } \\
\hline Fever-Yes & $\begin{array}{l}257 \\
(88.32)\end{array}$ & $95(92.23)$ & $162(86.17)$ & 0.13 \\
\hline
\end{tabular}




\begin{tabular}{|c|c|c|c|c|}
\hline $\begin{array}{l}\text { All Index cases } \\
\mathrm{n}=291\end{array}$ & & $\begin{array}{l}\text { Contact } \\
\text { based } \\
\text { surveillance } \\
n=103(\%)\end{array}$ & $\begin{array}{l}\text { Symptom based } \\
\text { surveillance } \\
n=188(\%)\end{array}$ & $\begin{array}{l}\text { p-value } \\
\text { (Fisher } \\
\text { Exact -test) }\end{array}$ \\
\hline Fever-No & $34(11.68)$ & $8(7.77)$ & $26(13.83)$ & \\
\hline Cough-Yes & $\begin{array}{l}178 \\
(61.17)\end{array}$ & $61(59.22)$ & $117(62.23)$ & 0.61 \\
\hline Cough-No & $\begin{array}{l}113 \\
(38.83)\end{array}$ & $42(40.78)$ & $71(37.77)$ & \\
\hline Fatigue-Yes & $88(30.24)$ & $51(49.51)$ & $37(19.68)$ & $<0.0001$ \\
\hline Fatigue-No & $\begin{array}{l}203 \\
(69.76)\end{array}$ & $52(50.49)$ & $151(80.32)$ & \\
\hline Diarrhea-Yes & $49(18.84)$ & $21(20.39)$ & $28(14.89)$ & 0.25 \\
\hline Diarrhea-No & $\begin{array}{l}242 \\
(83.16)\end{array}$ & $82(79.61)$ & $160(85.11)$ & \\
\hline $\begin{array}{l}\text { Breathing difficulty- } \\
\text { Yes }\end{array}$ & $101(34.71)$ & $39(37.86)$ & $62(32.98)$ & 0.44 \\
\hline Breathing difficulty-No & $\begin{array}{l}190 \\
(65.29)\end{array}$ & $64(62.14)$ & $126(67.02)$ & \\
\hline Cough-Yes & $\begin{array}{l}128 \\
(43.99)\end{array}$ & $47(45.63)$ & $81(43.09)$ & 0.003 \\
\hline Cough-No & $\begin{array}{l}163 \\
(56.01)\end{array}$ & $56(54.37)$ & $107(56.91)$ & \\
\hline Runny nose-Yes & $79(27.15)$ & $36(34.95)$ & $43(22.87)$ & 0.03 \\
\hline Runny nose-No & $\begin{array}{l}212 \\
(72.85)\end{array}$ & $67(65.05)$ & $145(77.13)$ & \\
\hline
\end{tabular}

When comparing cases between contact-based and symptom-based surveillance, male cases 134 (71.3\%) of 188 vs $79(76.7 \%)$ of 103 cases were detected through symptom-traced surveillance $(\mathrm{p}<$ 0.0001). Majority of cases were detected between age group 30-69 $(n=89$ [86.4\%] of 103 vs 131 [69.7\%] of 188; $p=0.05$; Table 1) in both modes of detection. In the contact-based surveillance group, 9 [90.3\%] of 103 cases showed the symptom of fever in compared to $165(87.7 \%)$ cases of symptom-based surveillance; $p=0.56$; Table 1).

\section{Analysis Of Key Parameters For Index Cases}

Going by the growth of the epidemic and based on patients with well-defined time of exposure and time of symptom onset, we estimated the onset to symptom period, median days in hospital stay, median 
onset to recovery and median onset to death for all index cases. In both surveillance modes, the majority of cases showed symptoms of the disease within 2 to 5 days, with the highest number of cases showing symptoms at day 4 (Fig. 1A). The estimated incubation period for COVID-19 cases was found to be 3.9 days and 4.1 days for contact-based and symptom-based surveillance respectively $(95 \% \mathrm{Cl} 2.18-4.42$; Fig. 1B; Supplementary Table S1). On the other hand, the serial interval for symptom-based surveillance was estimated as 3.0 days $(95 \% \mathrm{Cl} 2.57-4.71)$, while cases detected through contact-based surveillance was 2.0 days ( $95 \% \mathrm{Cl} 1.79-3.23$; Fig. 1C; Supplementary Table S1). $90 \%$ of patients showed symptoms within 6 days. Median hospital stays of 63 (21.7\%) out of 291 cases was 9.5 days (95\% $\mathrm{Cl} 8.99-9.94$; Supplementary Fig. S1A), and average onset to recovery of all cases was 21.1 days ( $95 \% \mathrm{Cl} 21.66-22.20$; Supplementary Fig. S1B).

As of September, 2020, when assessing the final clinical outcome, 17 patients died from both surveillance categories. The mean time from onset-to-death to be 15.7 days ( $95 \% \mathrm{Cl} 14.34-17.39$, Supplementary Fig S1C). The median age of the patients was 47.9 years (95\% $\mathrm{Cl} 43.77-77.06)$. Among all 17 cases of death, the male-female proportion was 14:3. We estimated the overall crude CFR (case fatality ratio) as $5.84 \%$ (95\% Cl 4.69-6.99; Supplementary Table S2). The highest CFR was estimated in 70-79 age group (25.0\%, 95\% Cl 20.62-29.38), age $80+(16.67 \%, 95 \% \mathrm{Cl} 120.5-21.29)$ and age $60-69$ years $(14.81 \%, 95 \%$ Cl 11.03-18.58; Supplementary Table S2; Supplementary Fig. S1D). The least CFR was estimated for the younger age group between 0-49 inclusive (Supplementary Table S2, Supplementary Fig. S1D). A large proportion of deaths were recorded in the older $(60+$ age $)$ cases $(18.46 \%, 95 \% \mathrm{Cl} 16.03-20.89)$ (Supplementary Table S2).

\section{Secondary infection rate and risk of transmission of close contacts in major exposure settings}

We collected 1171 close contact cases who were linked to 291 index cases between the same time period. Of the 1171 close contacts, 79 (6.75\%) were identified as funeral ceremonies contacts, 205 (17.1\%) household contacts, 131 (11.19\%) hospital facilities contacts, 177 (15.12\%) workplaces contacts, 181 (15.56\%) were family close contacts and remaining 398 (33.99\%) cases belongs to others category (social gathering, food court, market places, public transportations). Table 2 summarizes detailed epidemiological characteristics of all close contact cases in different exposure settings. We identified six (6) clusters and the distribution of clusters in each exposure according to the number of index cases is presented and summarized in Fig. 2A (Supplementary Fig. S2; Table 3). Through contact tracing, we identified 39 secondary cases from 1171 close contacts in different exposure settings (Fig. 2B). Six clusters of exposure settings with one or more secondary cases (not including tertiary cases or subsequent cases) were identified (Table 3). All cases in these clusters were locally transmitted. Three asymptomatic of 39 cases were excluded from the subsequent transmission analysis because none of the three asymptomatic cases transmitted to secondary cases. Of the 33 secondary cases, 11 (33.33\%) were in household setting, 3 (9.09\%) in the hospital, 2 (6.08\%) in funeral, 7 (21.21\%) in work places, 7 $(21.21 \%)$ in family and $6(18.8 \%)$ in others (public transportations, market places, food court etc.) exposure settings (Fig. 2B; Table 4). We closely monitored these secondary contacts when they were under quarantine or isolated at least for two weeks and during this time all 36 out of 39 of the close 
contacts showed all the major symptoms of COVID-19 and tested positive for COVID-19 infection. For symptomatic secondary cases with confirmed COVID-19 diagnosis, the distribution of days of symptom to RT-PCR diagnosis, symptom onset and isolation start time is presented in Supplementary Figure S3. 
Table 2

Characteristics of the 1171 close contacts by different exposure settings

\begin{tabular}{|c|c|c|c|c|c|c|c|}
\hline \multirow[t]{2}{*}{ Variables } & \multicolumn{7}{|c|}{ Exposure. №. (\%) } \\
\hline & $\begin{array}{l}\text { Funeral } \\
\text { Ceremony } \\
n=79\end{array}$ & $\begin{array}{l}\text { Household } \\
\mathrm{n}=205\end{array}$ & $\begin{array}{l}\text { Hospital } \\
\text { facilities } n= \\
131\end{array}$ & $\begin{array}{l}\text { Work } \\
\text { places n } \\
=177\end{array}$ & $\begin{array}{l}\text { Family } \mathrm{n} \\
=181\end{array}$ & $\begin{array}{l}\text { Others }^{1} \\
\mathrm{n}=398\end{array}$ & $\begin{array}{l}\mathrm{p}- \\
\text { value }\end{array}$ \\
\hline \multicolumn{8}{|l|}{ Sex } \\
\hline Male & $\begin{array}{l}51 \\
(61.56)\end{array}$ & $\begin{array}{l}142 \\
(69.27)\end{array}$ & $91(69.47)$ & $\begin{array}{l}129 \\
(72.88)\end{array}$ & $\begin{array}{l}107 \\
(59.12)\end{array}$ & $\begin{array}{l}252 \\
(63.32)\end{array}$ & \multirow[t]{2}{*}{0.05} \\
\hline Female & $\begin{array}{l}28 \\
(35.44)\end{array}$ & $63(30.73)$ & $40(30.53)$ & $\begin{array}{l}48 \\
(27.12)\end{array}$ & $\begin{array}{l}74 \\
(40.88)\end{array}$ & $\begin{array}{l}146 \\
(36.68)\end{array}$ & \\
\hline \multicolumn{8}{|c|}{ Age group-years } \\
\hline $0-9$ & 0 & $9(4.39)$ & 0 & 0 & $1(0.55)$ & $9(2.26)$ & \multirow[t]{9}{*}{0.0004} \\
\hline $10-19$ & 0 & $7(3.41)$ & $3(2.29)$ & 0 & $7(3.87)$ & $\begin{array}{l}58 \\
(14.57)\end{array}$ & \\
\hline $20-29$ & $\begin{array}{l}11 \\
(10.26)\end{array}$ & $29(14.15)$ & $10(7.63)$ & $\begin{array}{l}51 \\
(28.81)\end{array}$ & $\begin{array}{l}25 \\
(13.81)\end{array}$ & $\begin{array}{l}106 \\
(26.63)\end{array}$ & \\
\hline $30-39$ & $\begin{array}{l}17 \\
(17.95)\end{array}$ & $36(17.56)$ & $27(20.61)$ & $\begin{array}{l}47 \\
(26.55)\end{array}$ & $\begin{array}{l}34 \\
(18.78)\end{array}$ & $\begin{array}{l}79 \\
(19.85)\end{array}$ & \\
\hline $40-49$ & $\begin{array}{l}23 \\
(30.77)\end{array}$ & $33(16.10)$ & $25(19.08)$ & $\begin{array}{l}62 \\
(35.03)\end{array}$ & $\begin{array}{l}38 \\
(20.99)\end{array}$ & $\begin{array}{l}59 \\
(14.82)\end{array}$ & \\
\hline $50-59$ & $\begin{array}{l}21 \\
(20.51)\end{array}$ & $35(17.07)$ & $18(13.74)$ & $17(9.60)$ & $\begin{array}{l}27 \\
(14.92)\end{array}$ & $\begin{array}{l}68 \\
(17.09)\end{array}$ & \\
\hline $60-69$ & $7(20.51)$ & $26(12.68)$ & $19(14.50)$ & 0 & $\begin{array}{l}19 \\
(10.50)\end{array}$ & $\begin{array}{l}19 \\
(4.78)\end{array}$ & \\
\hline $70-79$ & 0 & $19(9.27)$ & $23(17.56)$ & 0 & $\begin{array}{l}21 \\
(11.60)\end{array}$ & 0 & \\
\hline $80+$ & 0 & $16(7.80)$ & $6(4.58)$ & 0 & $9(4.97)$ & 0 & \\
\hline \multicolumn{8}{|l|}{ Severity } \\
\hline Severe & $\begin{array}{l}29 \\
(36.71)\end{array}$ & $49(23.90)$ & $29(22.14)$ & $\begin{array}{l}39 \\
(22.03)\end{array}$ & $\begin{array}{l}27 \\
(14.92)\end{array}$ & $\begin{array}{l}37 \\
(9.30)\end{array}$ & \multirow[t]{3}{*}{0.0004} \\
\hline Moderate & $\begin{array}{l}31 \\
(39.24)\end{array}$ & 75 (36.59) & $37(28.24)$ & $\begin{array}{l}63 \\
(35.59)\end{array}$ & $\begin{array}{l}68 \\
(37.57)\end{array}$ & $\begin{array}{l}118 \\
(29.65)\end{array}$ & \\
\hline Mild & $\begin{array}{l}19 \\
(24.05)\end{array}$ & $81(39.51)$ & $65(49.62)$ & $\begin{array}{l}75 \\
(42.37)\end{array}$ & $\begin{array}{l}86 \\
(47.51)\end{array}$ & $\begin{array}{l}243 \\
(61.06)\end{array}$ & \\
\hline
\end{tabular}




\begin{tabular}{|c|c|c|c|c|c|c|c|}
\hline \multirow[t]{2}{*}{ Variables } & \multicolumn{7}{|c|}{ Exposure. No. (\%) } \\
\hline & $\begin{array}{l}\text { Funeral } \\
\text { Ceremony } \\
\mathrm{n}=79\end{array}$ & $\begin{array}{l}\text { Household } \\
n=205\end{array}$ & $\begin{array}{l}\text { Hospital } \\
\text { facilities } n= \\
131\end{array}$ & $\begin{array}{l}\text { Work } \\
\text { places } \mathrm{n} \\
=177\end{array}$ & $\begin{array}{l}\text { Family } n \\
=181\end{array}$ & $\begin{array}{l}\text { Others }^{1} \\
n=398\end{array}$ & $\begin{array}{l}\mathrm{p}- \\
\text { value }\end{array}$ \\
\hline Yes & $\begin{array}{l}31 \\
(39.24)\end{array}$ & 68 (33.17) & 33 (25.19) & $\begin{array}{l}29 \\
(16.38)\end{array}$ & $51(28.18)$ & $\begin{array}{l}119 \\
(29.90)\end{array}$ & 0.0004 \\
\hline No & $\begin{array}{l}48 \\
(60.76)\end{array}$ & $\begin{array}{l}137 \\
(66.83)\end{array}$ & $98(74.81)$ & $\begin{array}{l}148 \\
(83.62)\end{array}$ & $\begin{array}{l}130 \\
(71.82)\end{array}$ & $\begin{array}{l}279 \\
(70.10)\end{array}$ & \\
\hline
\end{tabular}

Table 3

Clusters, close contacts, and secondary cases distribution in differ exposure settings

\begin{tabular}{|llllll|}
\hline \multicolumn{5}{|c|}{ Color codes: Clusters, Close contacts, Secondary cases } \\
\hline Cluster size & Household & Hospital & Funeral & Work places & Family \\
\hline $\mathbf{1}$ & $13 / 12 / 2$ & $4 / 19 / 0$ & $2 / 13 / 1$ & $9 / 23 / 0$ & $7 / 31 / 0$ \\
\hline $\mathbf{2}$ & $19 / 71 / 3$ & $8 / 12 / 0$ & $1 / 9 / 0$ & $13 / 39 / 1$ & $6 / 29 / 2$ \\
\hline $\mathbf{3}$ & $21 / 63 / 3$ & $13 / 29 / 1$ & $3 / 11 / 0$ & $10 / 26 / 1$ & $9 / 39 / 2$ \\
\hline $\mathbf{4}$ & $29 / 33 / 2$ & $3 / 32 / 2$ & $7 / 19 / 1$ & $21 / 17 / 1$ & $17 / 26 / 1$ \\
\hline $\mathbf{5}$ & $13 / 16 / 1$ & $5 / 21 / 2$ & $5 / 11 / 0$ & $19 / 29 / 1$ & $9 / 35 / 2$ \\
\hline $\mathbf{6}$ & $10 / 10 / 0$ & $3 / 18 / 0$ & $4 / 16 / 0$ & $10 / 43 / 3$ & $4 / 21 / 0$ \\
\hline Total & $105 / 205 / 11$ & $36 / 131 / 3$ & $21 / 79 / 2$ & $77 / 177 / 7$ & $52 / 181 / 7$ \\
\hline
\end{tabular}


Table 4

Secondary clinical attack rate among 1171 close contacts by age, exposure setting and disease severity

\begin{tabular}{|c|c|c|c|c|c|}
\hline Variables & $\begin{array}{l}\text { No. of close } \\
\text { contacts (\%) }\end{array}$ & $\begin{array}{l}\text { No. of secondary } \\
\text { contacts (asymptomatic } \\
\text { case) }\end{array}$ & $\begin{array}{l}\text { Secondary } \\
\text { attack rate; \% } \\
(95 \% \mathrm{Cl})\end{array}$ & $\begin{array}{l}\mathrm{p}- \\
\text { values }^{1}\end{array}$ & $\begin{array}{l}\text { Risk ratio } \\
(95 \% \mathrm{Cl})\end{array}$ \\
\hline Overall & 1171 & $36(3)$ & $3.07(2.49-3.64)$ & & \\
\hline \multicolumn{6}{|l|}{ Sex } \\
\hline Male & $819(69.94)$ & $31(2)$ & $3.76(3.08-4.44)$ & \multirow[t]{2}{*}{0.04} & $\begin{array}{l}2.64 \\
(2.07- \\
3.21)\end{array}$ \\
\hline Female & $352(30.05)$ & $5(1)$ & $1.42(0.38-2.46)$ & & $\begin{array}{l}1 \\
\text { (reference) }\end{array}$ \\
\hline \multicolumn{6}{|l|}{ Age (years) } \\
\hline $0-9$ & 0 & 0 & 0 & \multirow[t]{9}{*}{0.019} & 0 \\
\hline $10-19$ & $57(4.87)$ & 0 & 0 & & 0 \\
\hline $20-29$ & $112(9.56)$ & $2(0)$ & $1.79(0.06-3.65)$ & & $\begin{array}{l}0.62 \\
(-0.47- \\
1.71)\end{array}$ \\
\hline $30-39$ & 139 (11.87) & $4(1)$ & $2.89(1.22-4.56)$ & & $\begin{array}{l}1 \\
\text { (reference) }\end{array}$ \\
\hline $40-49$ & $267(22.80)$ & $3(1)$ & $1.12(0.07-2.32)$ & & $\begin{array}{l}0.39 \\
(-0.31- \\
1.09)\end{array}$ \\
\hline $50-59$ & $251(21.43)$ & $15(1)$ & $5.98(4.74-7.22)$ & & $\begin{array}{l}2.07 \\
(1.34- \\
2.80)\end{array}$ \\
\hline $60-69$ & 117 (9.99) & $8(0)$ & $6.83(5.02-8.64)$ & & $\begin{array}{l}2.36 \\
(1.29- \\
3.43)\end{array}$ \\
\hline $70-79$ & $115(9.82)$ & $4(0)$ & $3.47(1.65-5.29)$ & & $\begin{array}{l}1.20 \\
(1.12- \\
2.28)\end{array}$ \\
\hline $80+$ & 0 & 0 & 0 & & 0 \\
\hline \multicolumn{6}{|c|}{ Exposure settings } \\
\hline Household & $178(15.20)$ & $11(1)$ & $6.17(4.70-7.64)$ & \multirow[t]{2}{*}{0.05} & $\begin{array}{l}2.44 \\
(1.51- \\
3.36)\end{array}$ \\
\hline $\begin{array}{l}\text { Hospital } \\
\text { facility }\end{array}$ & $131(11.19)$ & $3(1)$ & $2.29(0.58-3.40)$ & & $\begin{array}{l}0.91 \\
(-0.17- \\
1.99)\end{array}$ \\
\hline
\end{tabular}




\begin{tabular}{|c|c|c|c|c|c|}
\hline Variables & $\begin{array}{l}\text { No. of close } \\
\text { contacts (\%) }\end{array}$ & $\begin{array}{l}\text { No. of secondary } \\
\text { contacts (asymptomatic } \\
\text { case) }\end{array}$ & $\begin{array}{l}\text { Secondary } \\
\text { attack rate; \% } \\
(95 \% \mathrm{Cl})\end{array}$ & $\begin{array}{l}\mathrm{p}- \\
\text { values }^{1}\end{array}$ & $\begin{array}{l}\text { Risk ratio } \\
(95 \% \mathrm{Cl})\end{array}$ \\
\hline Funeral & $79(6.75)$ & $2(0)$ & $2.53(0.32-4.73)$ & & $\begin{array}{l}1 \\
\text { (reference) }\end{array}$ \\
\hline $\begin{array}{l}\text { Work } \\
\text { places }\end{array}$ & $177(15.12)$ & $7(0)$ & $3.95(2.48-5.42)$ & & $\begin{array}{l}1.56 \\
(0.63- \\
2.49)\end{array}$ \\
\hline Family & $181(15.46)$ & $7(1)$ & $3.87(2.41-5.33)$ & & $\begin{array}{l}1.53 \\
(0.61- \\
2.45)\end{array}$ \\
\hline Other & $425(36.29)$ & $6(0)$ & $1.41(0.45-2.36)$ & & $\begin{array}{l}0.56 \\
(-0.04- \\
1.16)\end{array}$ \\
\hline \multicolumn{6}{|c|}{ Disease severity } \\
\hline Severe & 259 (22.12) & $11(0)$ & $4.25(3.03-5.47)$ & $\hat{0}_{0.0001}$ & $\begin{array}{l}1.45 \\
(0.74- \\
2.16)\end{array}$ \\
\hline Moderate & $647(55.25)$ & $19(1)$ & $2.93(2.16-3.70)$ & & $\begin{array}{l}1 \\
\text { (reference) }\end{array}$ \\
\hline Low & $265(22.63)$ & $6(2)$ & $2.26(1.06-3.46)$ & & $\begin{array}{l}0.77 \\
(0.06- \\
1.47)\end{array}$ \\
\hline
\end{tabular}

Using the data from 33 cases with well-defined exposure history, we estimated the estimated median incubation period of these 33-secondary cases for overall and for each exposure setting. The overall incubation period was 3.9 days ( $95 \% \mathrm{Cl} 3.41-4.79$; Supplementary Table S3) and median serial interval was 4.1 day (95\% $\mathrm{Cl} 3.41-4.79$, Supplementary Table S4; Figs. 3A; 3B). The incubation period for household setting was estimated as 1.5 days $(95 \% \mathrm{Cl} 1.52-3.48)$ and serial interval was 3.3 days $(95 \% \mathrm{Cl}$ 2.20-4.46; Figs. 3A; 3B; Supplementary Table S3; S4). The overall secondary clinical attack rate was $3.07 \%$ (95\% $\mathrm{Cl} 2.49-3.64)$ among all cases analyzed (Table 4). A higher percentage of males than females (3.76\% [95\% Cl 3.08-4.44] to 1.42\% [95\% Cl 0.38-2.46]) were infected, and these differences were statistically significant $(p=0.04$; Table 4$)$. The secondary attack rate was $(6.83 \% \%[95 \% \mathrm{Cl} 5.02-$ 8.64; risk ratio 2.36, [95\% $\mathrm{Cl} 1.29-3.43]$ ) higher in cases who were ages between 60 to 69 , followed by ages age $50-59$ (5.98\% [95\% $\mathrm{Cl} 4.47-7.22$; risk ratio 2.07, [95\% $\mathrm{Cl} 1.34-2.80])$ and age $70-79$ (3.47\%, [95\% $\mathrm{Cl} 1.65-5.29 .75$; risk ratio $1.20,95 \% \mathrm{Cl} 1.12-2.28]$; Table 4). In term of exposure settings, household contact had a higher secondary attack rate $(6.17 \% ; 95 \% \mathrm{Cl} 4.70-7.64)$ and higher risk of secondary infection (risk ratio $2.44 ; 95 \% \mathrm{Cl} 1.51-3.36$ ) compared to cases who were exposed to hospital facility (2.29\%; 95\% Cl 0.58-3.40, risk ratio 0.91; 95\% Cl -0.17-1.99), workplaces contacts $(3.95 \%, 95 \% \mathrm{Cl} 2.48-$ 
5.42; risk ratio $1.56,95 \% \mathrm{Cl} 0.63-2.49)$, family contacts $(3.87 \%, 95 \% \mathrm{Cl} 2.41-5.33$, risk ratio $1.53 ; 95 \% \mathrm{Cl}$ $0.61-2.45)$ and other contact $(1.41 \%, 95 \% \mathrm{Cl} 0.45-2.36$, risk ratio $0.5695 \% \mathrm{Cl}-0.04-1.16$; Table 4$)$. The secondary attack rate and risk ratio increased with the disease severity of the index cases. The secondary attack rate and risk ratio was $4.25 \%$ and 2.93 (95\% $\mathrm{Cl} 3.03-5.47 ; 1.45 ; 95 \% \mathrm{Cl} 0.74-2.16)$ for severe cases while the secondary attack rate was $2.26 \%(95 \% \mathrm{Cl} 1.06-3.46)$ and risk ratio was $0.77(95 \% \mathrm{Cl}$ $0.06-1.17$ ) for low risk cases (Table 4).

\section{Discussion}

This is the first comprehensive contact tracing and secondary transmission dynamics analysis of COVID19 in different exposure settings from Bangladesh. Our analysis of confirmed COVID-19 cases among close contacts revealed an insight into the demographic characteristics, sign of symptoms, infection periods and secondary transmission risk at different exposure settings. We found that the overall secondary attack rate was lower than $4 \%$ (actual attack rate was $3.07 \%$ ). However, the secondary attack rate was higher among household contact followed by workplace and family close contacts. Moreover, the secondary attack rate was higher in higher age groups and more severe cases and likely to contribute in increasing the risk of infecting other close contacts.

The incubation period of COVID-19 is critical in deciding the types of measures to be considered for the safe and exact isolation period who are likely to be exposed. Most recent studies reported an incubation period that is fairly shorter ( 3.0 to 6.4 days), but with a longer detrimental clinical course ${ }^{7-13}$. The time to recovery or death from this disease is comparatively longer and may take several days to weeks ${ }^{13}$. Our data from index cases estimated the incubation period notably shorter (3.9 days) and whereas 2.5 days for secondary contact cases which is shorter than most reported COVID-19 cases ${ }^{4,12}$. Cheng et al ${ }^{5}$ reported the median incubation period was 4.1 days for close contact cases from Taiwan reinforcing our assumption that close contact cases may have a shorter incubation period than primary cases. On the other hand, our estimate of the serial interval was shorter than the recently published report (3.3 [our case] vs 4.0 vs 7.5 days) ${ }^{5,10,14}$. In our cases, the estimated distribution of incubation and serial interval distribution for household contact cases is shorter than other previously reported settings. This differences in the incubation period and serial interval in household settings perhaps due to repeated and longer time interaction/exposure with the symptomatic cases. As we did not analyze the incubation periods between sex and different age groups, we suggest that determining the sex and age specific incubation periods would provide additional intervention measures to conduct the epidemiological study.

Analyzing secondary transmission dynamics may provide valuable insights for characterizing the epidemiological modeling parameters, risk factors and disease transmission estimation ${ }^{1,6}$. Most studies assessed the transmissibility of COVID-19 primarily using a mathematical model at the population level 15-17. A handful of studies investigated the other type of transmissibility such as household or through other types of close contacts ${ }^{13,18}$. Data obtained from contact tracing provides the most accurate and up to date information about person-to-person transmission possibility by obtaining and accounting 
individual-level exposure history. In Bangladesh, the COVID-19 transmission occurred most likely amongst close contacts, such as in the household setting, hospital facility, family members, funeral ceremonies, workplaces and public transportations. To ascertain these possibilities, we assessed and estimated the secondary attack rate of COVID-19 in Bangladesh among several exposure settings. The secondary attack rate of COVID-19 among household contacts was $6.07 \%$ in our study which is higher than in Taiwan ${ }^{5}$ but lower than China [11.2\% ${ }^{4}$ and $10.5 \%$ in the United States ${ }^{19}$ and Guangzhou, China ${ }^{20}$. Although, the overall secondary clinical attack rate was relatively low, adult cases and particularly the age group between 50 and 70 are at higher risk of being infected in general. Surprisingly, we observed that other exposure settings such as hospital facilities, funeral ceremonies and family contacts and public transportations had lesser risk of secondary transmission. Our results showed that patients with severe COVID-19 cases are more likely to have higher transmission possibilities due to higher viral loads than those of moderate and mild type cases supporting previously reported results $1,13,21$. The high transmission of COVID-19 amongst household contacts during the study period was most likely due to the mass movement of people during the government lockdown announcements as well too many household members living and sharing in under the same household. Other reasons could be people did not follow the guidance of proper personal protective measures and not following the government's strict containment measures in the country.

Our present work has several notable limitations. First, reliance on estimates from discrete but a small cohort of cases, and on cases with incomplete information of clinical symptoms, age or both. However, given the difficulties of tracing of cases and the urgent timeline, we had to rely on the small cohort to provide real-time information on the COVID-19 pandemic situation in Bangladesh. In several cases we did not reach the patients to obtain additional missing information. Second, in some cases, we were unable to thoroughly examine the contacts before onset of symptoms in the contact-based surveillance and symptom-based surveillance cases, therefore limiting the analysis of early transmission. This limitation might contribute to underestimation of new infections from early transmission. Third, we were unable to obtain actual data to quantify the infectivity of the asymptomatic infection cases and silent transmission from asymptomatic cases from different exposure settings.

In summary, our results showed that overall secondary attack rate of COVID-19 in Bangladesh was comparatively low, but household contacts as well as severe cases are at higher risk of both infection and transmission and need more coordinated attention to stop the spread of virus. At the time of the preparation of this report the country is still experiencing the growth and transmission of the pandemic. As the cases continue to grow, it is fairly important that we need to obtain more knowledge about the pattern of transmission in different exposure settings.

\section{Methods}

\section{Cases from individual labels and study population}


On April 3, 2020, BITID (Bangladesh Institute of Tropical and Infectious Diseases) identified the first COVID-19 case in Chattogram, Bangladesh. The government since then expanded the testing and surveillance of all close contacts regardless of symptoms in the neighborhood. All suspected cases and close contacts were tested for COVID-19 and followed up until 14 days after last exposure to the index cases. All close contacts were identified through contact tracing who lived in the same house or apartment or in the same building, and who attended any funeral ceremony or socially interacted before any COVID-19 like symptom onset. Detailed demographic and clinical data and exposure history were recorded and reported for all confirmed cases. This work was conducted as part of the ongoing public health response, therefore institutional or regional review board approval and individual cases consent approval was waived. This study was approved by the central ethics committee of Bangladesh Medical Research Council (study \# 2021-2023/62(1-20) - a waiver of informed consent from patients was also approved. All research was performed in accordance with the relevant ethical guidelines and regulations.

\section{Epidemiological And Clinical Features Of All Contact Tracing Cases}

All RT-PCR testing was done by IEDCR [IEDCR 2020] and its approved affiliated field centers across the country. The symptom-based surveillance was defined as cases who were screened in the government certified test centers (not in the airports or any borders entry point) such as testing of patients admitted to hospitals, and other test centers. We defined contact-based surveillance as cases who were screened through monitoring and testing of close contacts of any confirmed cases irrespective of the showing any symptoms. In this analysis, close contact was defined as individuals who were closely linked by contact tracing and were considered a close contact group provided that no personal protective equipment (PPE) was worn having direct face to face contacts. Household contacts were defined as individuals who lived and were sharing the same room and same apartment in the same household with the index cases. Family contacts were those who are the members of the same family not living in the same household. Once a close contact is identified, a thorough clinical assessment was conducted for common symptoms as presented in Table 1, and at the same time patients' disease severity was assessed. We have classified disease severity in 3 main categories. (a) mild cases if the patients do not show any serious symptoms described in moderate or severe categories; (b) moderate cases if the patients show fever, some respiratory symptoms and any evidence of pneumonia by radiography; and (c) severe cases defined as cases experiencing any of the following symptoms: breathing rate 30 or higher breaths/minute, the oxygen saturation level below $93 \%$, one or multiple organ failures, requiring mechanical ventilation, a ratio of the partial pressure of arterial oxygen to the fraction of inspired oxygen ( $\mathrm{PaO2}: \mathrm{FiO} 2)$ of less than 300 $\mathrm{mm} \mathrm{Hg}$, or infiltrates in more than $50 \%$ of the lung field within 24 to 48 hours.

\section{Statistical analysis, data processing and analysis of timing of key events}

\section{Determining of serial interval and incubation period (symptom onset).}

All summary analyses were done using R statistical software (version 4.0.2). We used R-packages "ggplot2" for generating graphs. To compare the characteristics between demographic groups and patients' underlying disorders we used non-parametric (Fisher's Exact test). Distributions were fitted to the 
key events in all confirmed cases. For our primary analysis, we assumed that the incubation time (infection to symptom onset) follows the log-normal distribution as observed in other acute respiratory viral infection ${ }^{5,22}$. We estimated the prior and posterior boundaries on the symptom onset time. Time between symptom onset, days in hospital, onset to recovery and onset to deaths were estimated by fitting gamma distribution using Bayesian methods. All confidence intervals were analyzed with bootstrapping

or standard parametric estimators described previously ${ }^{13,23}$. Estimation of Case Fatality Ratio (CFR) was determined using recently reports by Verity et al $2020{ }^{24}$ and Mizumoto and Chowell $2020{ }^{25}$ which follows a gamma distribution. Following the WHO guidelines, we defined the secondary clinical attack rate as the ratio of symptomatic confirmed cases among the close contacts ${ }^{18,26}$. Incubation period and serial interval were estimated using the contact tracing data in Bangladesh. We used similar methods as mentioned above to increase the stability of the small estimation for contact tracing cases. We collected symptom onset dates of COVID-19 cases with confirmed transmission links in IEDCR and from local testing centers or directly contacting confirmed COVID-19 cases. The exposure settings were categorized as (a) household, (b) hospital facility, (c) funeral ceremony, (d) work places, (e) family members, and (f) others [friends, public transportation, food court etc.]. To analyze the serial interval and incubation period distribution by adopting the statistical methods by Backer et al and adopted from ${ }^{5}$. We fitted the gamma distribution model to all exposure settings categories to the observed serial interval $(S I)$ in a Bayesian method. For each category, $k=1,2,3,4$,

\section{$S I^{k} \sim \operatorname{Gamma}\left(\boldsymbol{\alpha}^{k}, \boldsymbol{\beta}^{k}\right)$ \\ $\boldsymbol{\alpha}^{\nless \sim}$ Exponential (1/ $\left.\boldsymbol{\theta}^{\text {hope }}\right)$ \\ $\boldsymbol{\beta}^{\star} \sim$ Exponential $\left(1 / \boldsymbol{\theta}^{\text {cale }}\right)$}

where in each categories $(k)$ has its own serial interval distribution. The stratum-specific distribution parameters, shape $\left(\boldsymbol{\alpha}^{k}\right)$ and scale $\left(\boldsymbol{\beta}^{k}\right)$ are related by an exponential hyperparameter's distribution, with mean $\boldsymbol{\theta}^{\text {khope }}$, and $\boldsymbol{\theta}^{\text {ccale }}$ respectively. Non-informative priors for hyper-parameters were used as:

$$
\begin{aligned}
& \boldsymbol{\theta}^{\text {shope }} \text { Half-normal }(0,1000) \\
& \boldsymbol{\theta}^{\text {cale }} \sim \text { Half-normal }(0,1000)
\end{aligned}
$$

Since the reported symptom onset dates can be intervals, we set uniform priors for the onset intervals, and estimated the symptom onset dates. For each individual $i=1, \ldots ., n$

$$
\begin{gathered}
X_{i}^{0} \sim \text { Uniform }\left(X L_{i}^{0}, X R_{i}^{0}\right) \\
X_{i}^{1} \sim \text { Uniform }\left(X L_{i}^{1}, X R_{i}^{1}\right) \\
S I=X_{i}^{1}-X_{i}^{0}
\end{gathered}
$$

where $X L_{i}^{0}, X R_{i}^{0}$ is the symptom onset interval for the infector in pair I, and $L_{i}^{1}, X R_{i}^{1}$ is the symptom onset interval for the infectee. 


\section{Declarations}

Author information

Affiliations

Bangamata National Cellular and Molecular Research Centre, Bangladesh

Abu Shadat M Noman

Department of Medicine, Park View Hospital, Chittagong, Bangladesh

Mohammed Rezaul Karim, ASM Zahed, ATM Rezaul Karim

Department of Molecular Oncology, King Faisal Specialist Hospital and Research Centre, Riyadh, Saudi Arabia. School of Medicine, Al-Faisal University, Riyadh, Saudi Arabia

Syed S Islam

Authors contribution. SSI conception and design of the study, SSI, ASMN. coordinated the works and lead the work in writing the manuscript and data interpretation. ATMRK, MRK and ATMZ received the patient's data information from hospital registry, SSI. performed all the statistical analyses. SSI, ASMN, ATMRK, MRK and ATMZ. reviewed the data and manuscript before the submission.

Acknowledgements. We sincerely thank IEDCR and all hospital staffs for coordinating the data collection. We also extend our heartiest thanks to BMRC for financial supporting to carry out the work.

Financial support.

The role of funding source

This work was supported by Bangladesh Medical Research Council. Grant no-2021-2023/62(1-20). The funding agency had no roles in study design, data collection and analysis, data interpretation and writing of the manuscript

Ethics declaration

Competing of interests

The authors declared no conflict of interest

\section{Data availability}

The data that supports our results of this study are available upon request from the corresponding author. 


\section{References}

1. WHO. WHO Coronavirus disease (COVID-19) outbreak situation. Coronavirus disease (COVID-19) outbreak situation (2020).

2. Wang, D. et al. Clinical Characteristics of 138 Hospitalized Patients with 2019 Novel CoronavirusInfected Pneumonia in Wuhan, China. JAMA - J. Am. Med. Assoc. (2020) doi:10.1001/jama.2020.1585.

3. Tabata, S. et al. Clinical characteristics of COVID-19 in 104 people with SARS-CoV-2 infection on the Diamond Princess cruise ship: a retrospective analysis. Lancet Infect. Dis. (2020) doi:10.1016/S1473-3099(20)30482-5.

4. Bi, Q. et al. Epidemiology and transmission of COVID-19 in 391 cases and 1286 of their close contacts in Shenzhen, China: a retrospective cohort study. Lancet Infect. Dis. (2020) doi:10.1016/S1473-3099(20)30287-5.

5. Cheng, H. Y. et al. Contact Tracing Assessment of COVID-19 Transmission Dynamics in Taiwan and Risk at Different Exposure Periods before and after Symptom Onset. JAMA Intern. Med. (2020) doi:10.1001/jamainternmed.2020.2020.

6. Wu, J. et al. Household Transmission of SARS-CoV-2, Zhuhai, China, 2020. Clin. Infect. Dis. (2020) doi:10.1093/cid/ciaa557.

7. Pan, A. et al. Association of Public Health Interventions with the Epidemiology of the COVID-19 Outbreak in Wuhan, China. JAMA - J. Am. Med. Assoc. (2020) doi:10.1001/jama.2020.6130.

8. Lee, H. et al. Incubation period of the coronavirus disease 2019 (COVID-19) in Busan, South Korea. J. Infect. Chemother. (2020) doi:10.1016/j.jiac.2020.06.018.

9. Ki, M. Epidemiologic characteristics of early cases with 2019 novel coronavirus (2019-nCoV) disease in Korea. Epidemiol. Health (2020) doi:10.4178/epih.e2020007.

10. Li, Q. et al. Early transmission dynamics in Wuhan, China, of novel coronavirus-infected pneumonia. New England Journal of Medicine (2020) doi:10.1056/NEJMoa2001316.

11. Linton, N. et al. Incubation Period and Other Epidemiological Characteristics of 2019 Novel Coronavirus Infections with Right Truncation: A Statistical Analysis of Publicly Available Case Data. J. Clin. Med. (2020) doi:10.3390/jcm9020538.

12. Backer, J. A., Klinkenberg, D. \& Wallinga, J. Incubation period of 2019 novel coronavirus (2019- nCoV) infections among travellers from Wuhan, China, 2028 January 2020. Eurosurveillance (2020) doi:10.2807/1560-7917.ES.2020.25.5.2000062.

13. Chen, N. et al. Epidemiological and clinical characteristics of 99 cases of 2019 novel coronavirus pneumonia in Wuhan, China: a descriptive study. Lancet (2020) doi:10.1016/S0140-6736(20)302117.

14. Nishiura, H., Linton, N. M. \& Akhmetzhanov, A. R. Serial interval of novel coronavirus (COVID-19) infections. Int. J. Infect. Dis. (2020) doi:10.1016/j.ijid.2020.02.060. 
15. Banerjee, A. et al. Estimating excess 1-year mortality associated with the COVID-19 pandemic according to underlying conditions and age: a population-based cohort study. Lancet (2020) doi:10.1016/S0140-6736(20)30854-0.

16. Wu, J. T., Leung, K. \& Leung, G. M. Nowcasting and forecasting the potential domestic and international spread of the 2019-nCoV outbreak originating in Wuhan, China: a modelling study. Lancet (2020) doi:10.1016/S0140-6736(20)30260-9.

17. Chinazzi, M. et al. The effect of travel restrictions on the spread of the 2019 novel coronavirus (COVID-19) outbreak. Science (80-. ). (2020) doi:10.1126/science.aba9757.

18. Tian, H. et al. An investigation of transmission control measures during the first 50 days of the COVID-19 epidemic in China. Science (80-. ). (2020) doi:10.1126/science.abb6105.

19. Burke, R. M. et al. Active Monitoring of Persons Exposed to Patients with Confirmed COVID-19 United States, January-February 2020. MMWR. Morb. Mortal. Wkly. Rep. (2020) doi:10.15585/mmwr.mm6909e1.

20. Luo, L. et al. Contact Settings and Risk for Transmission in 3410 Close Contacts of Patients With COVID-19 in Guangzhou, China. Ann. Intern. Med. (2020) doi:10.7326/m20-2671.

21. Yang, W. et al. Clinical characteristics and imaging manifestations of the 2019 novel coronavirus disease (COVID-19):A multi-center study in Wenzhou city, Zhejiang, China. J. Infect. (2020) doi:10.1016/j.jinf.2020.02.016.

22. Lessler, J. et al. Incubation periods of acute respiratory viral infections: a systematic review. The Lancet Infectious Diseases (2009) doi:10.1016/S1473-3099(09)70069-6.

23. Lauer, S. A. et al. The incubation period of coronavirus disease 2019 (CoVID-19) from publicly reported confirmed cases: Estimation and application. Ann. Intern. Med. (2020) doi:10.7326/M200504.

24. Verity, R. et al. Estimates of the severity of coronavirus disease 2019: a model-based analysis. Lancet Infect. Dis. (2020) doi:10.1016/S1473-3099(20)30243-7.

25. Mizumoto, K. \& Chowell, G. Estimating risk for death from coronavirus disease, China, JanuaryFebruary 2020. Emerg. Infect. Dis. (2020) doi:10.3201/EID2606.200233.

26. Efron, B. \& Gong, G. A leisurely look at the bootstrap, the jackknife, and cross-validation. Am. Stat. (1983) doi:10.1080/00031305.1983.10483087.

\section{Figures}


Figure 1

A

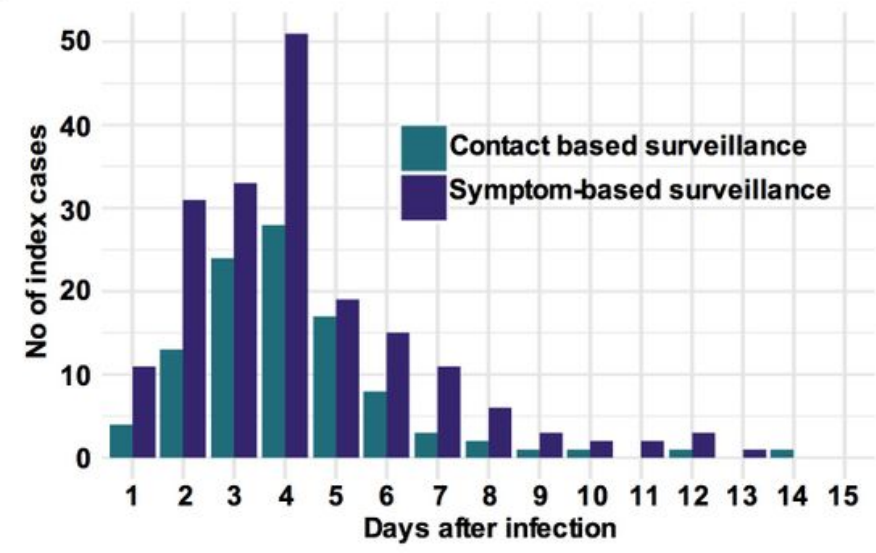

B
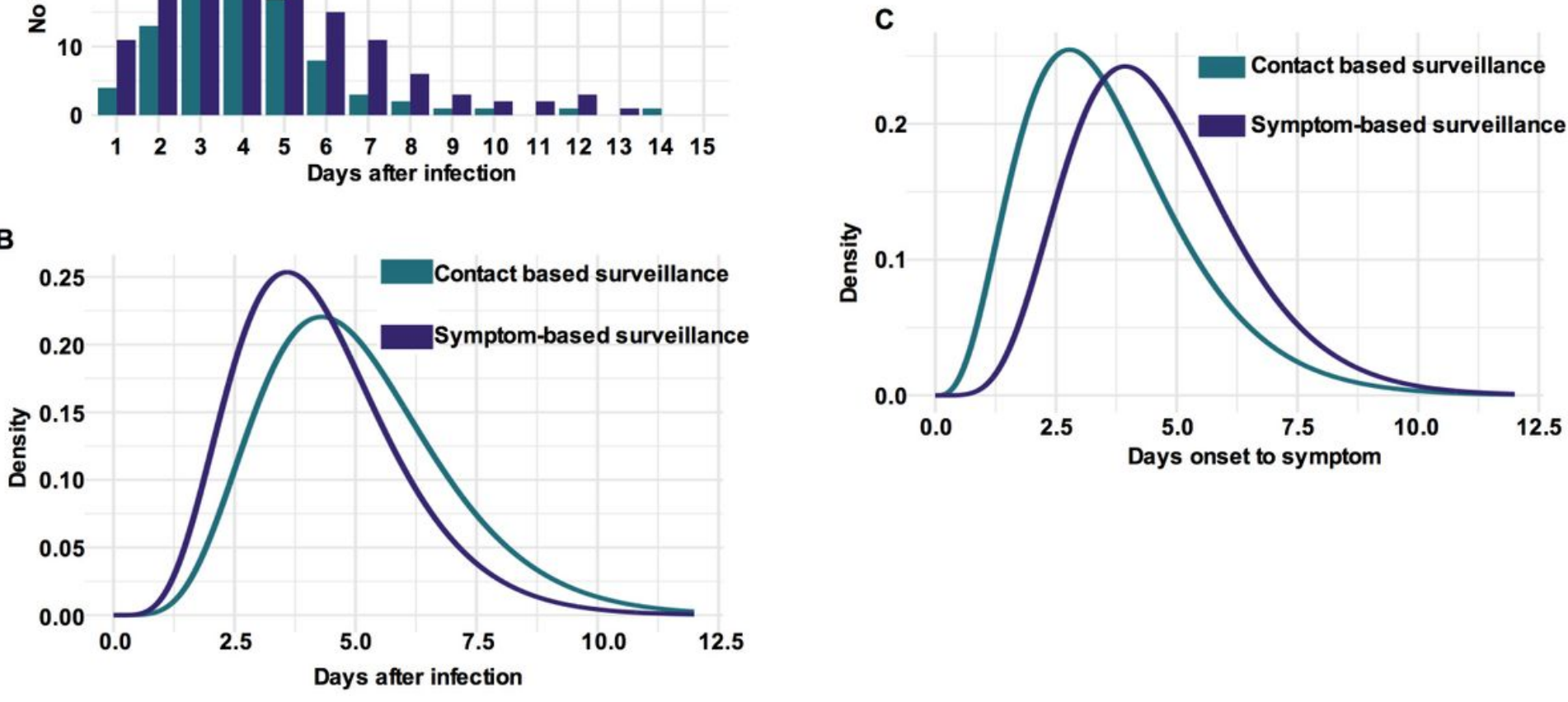

Figure 1

A. Number of index cases from contact-based and symptom-based surveillance based on the incubation period. B. Incubation period, and C. Serial interval distribution of index cases for both mode of detection. 
Figure 2:

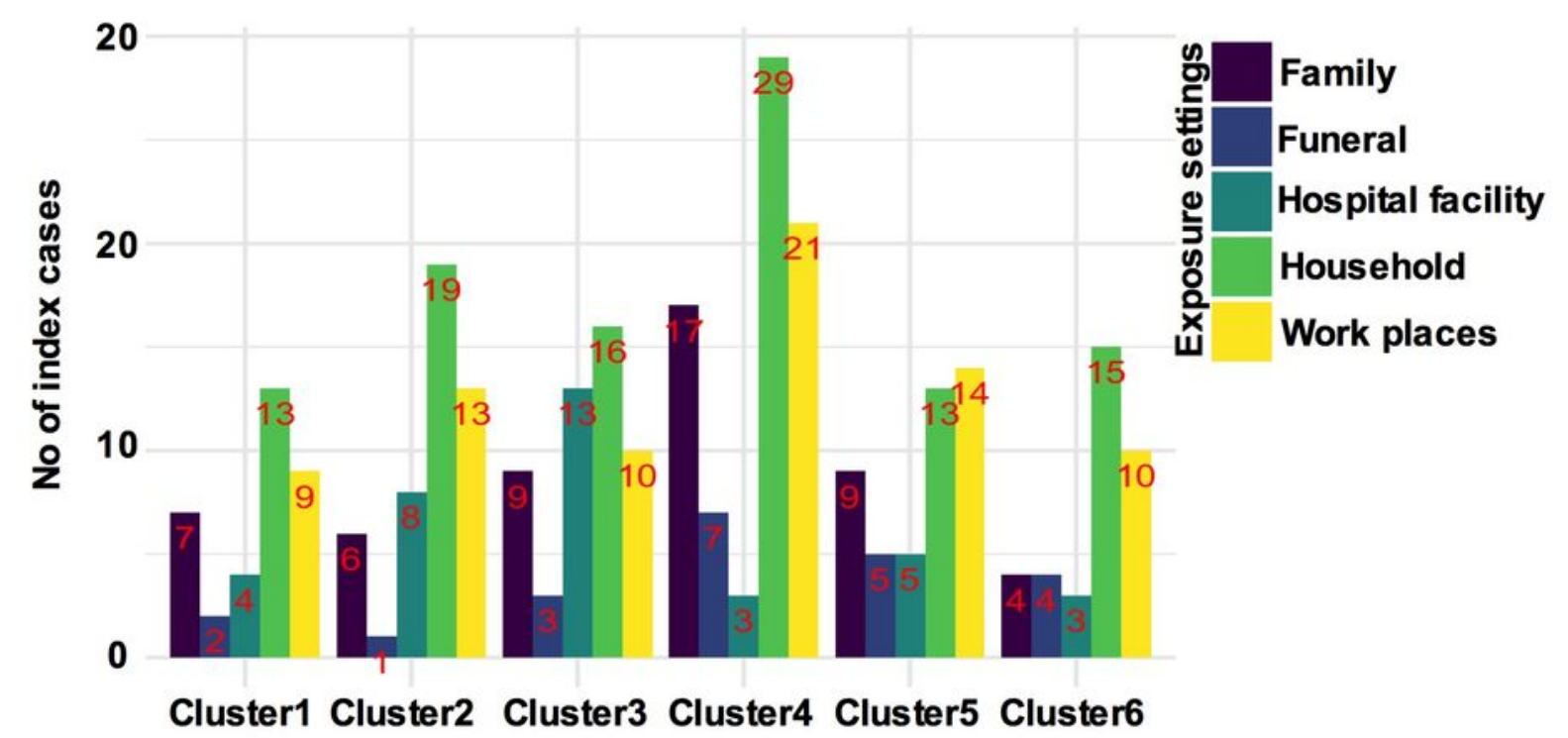

B

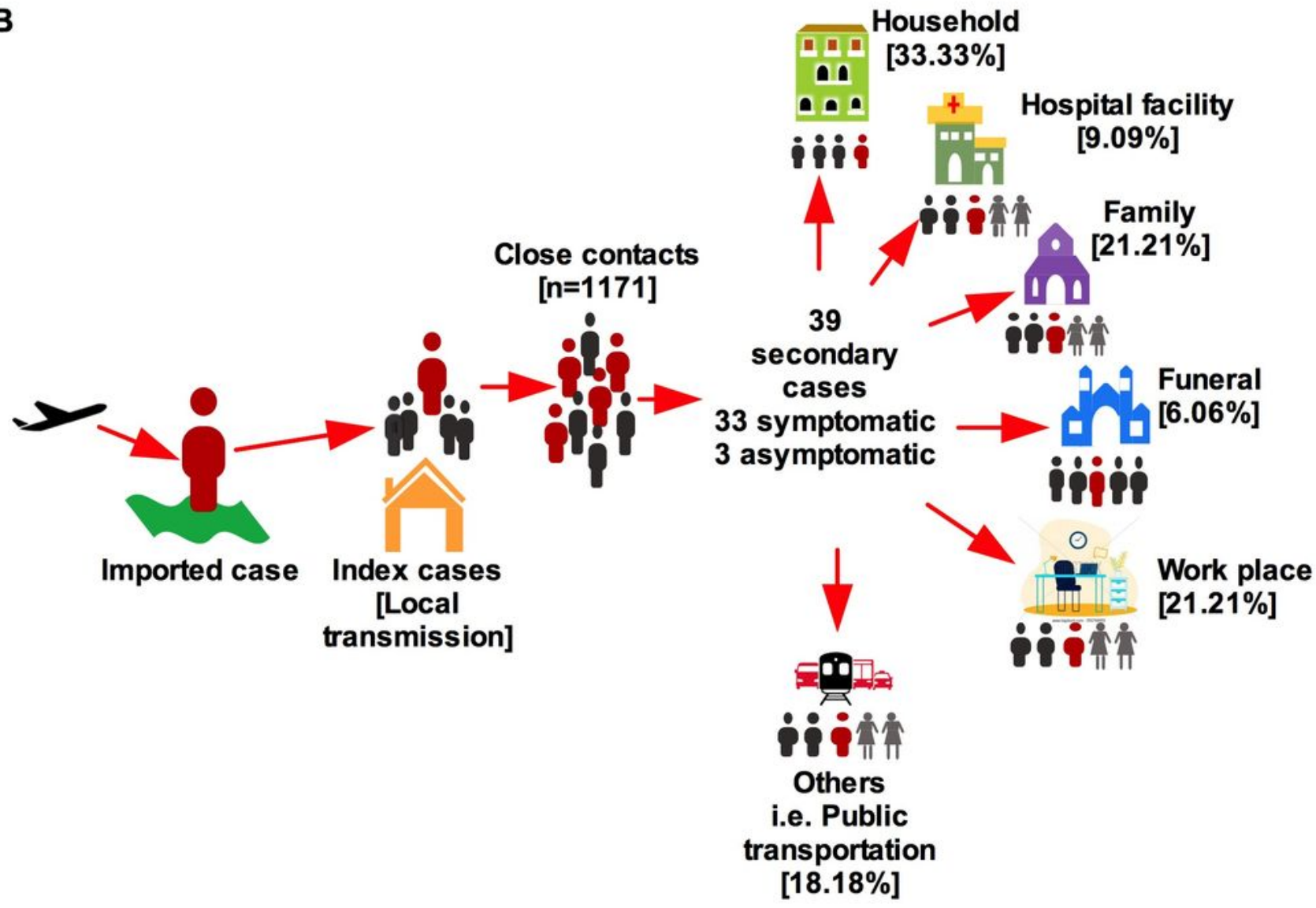

Figure 2

A. Distribution of clusters at different secondary exposure settings. B. Schematic diagram of the risk of transmission of COVID-19 cases from first imported cases and local primary and secondary transmission in different exposure settings. 
Figure 3

A Estimated incubation period distribution graph

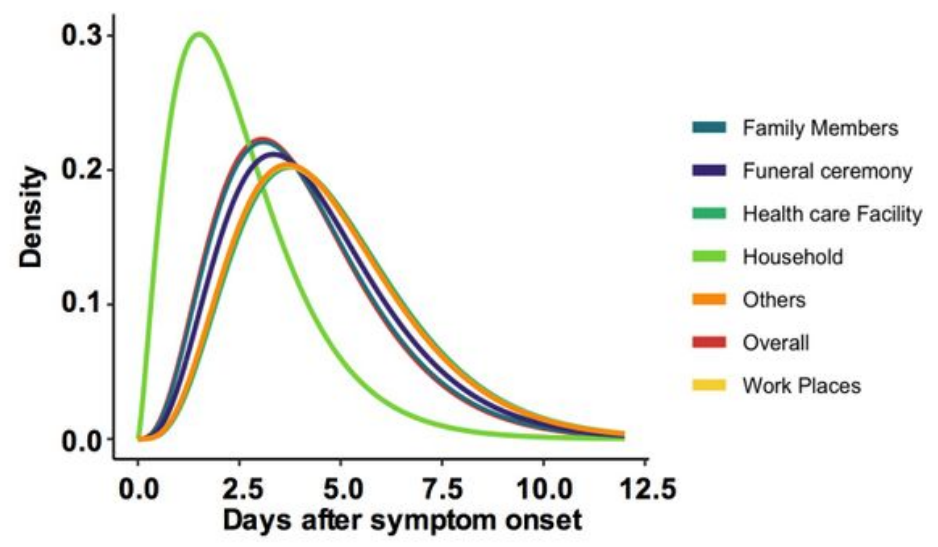

B Estimated serial interval distribution graph

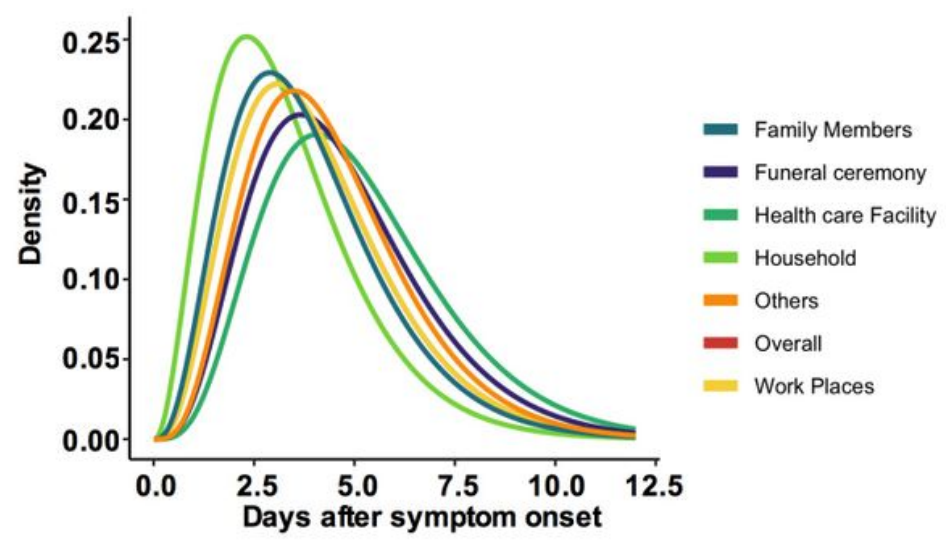

Figure 3

A. The estimated fitted gamma incubation period distributions, and B. the estimated fitted gamma serial interval distributions in different secondary exposure settings.

\section{Supplementary Files}

This is a list of supplementary files associated with this preprint. Click to download.

- SupplementaryFigureS1.tiff

- SupplementaryFigureS2.tiff

- SupplementaryFigureS3.tiff

- SupplementaryTableS1.docx

- SupplementaryTableS2.docx

- SupplementaryTableS3.docx

- SupplementaryTableS4.docx 